\title{
ABC Transporter Inhibition
}

National Cancer Institute

\section{Source}

National Cancer Institute. ABC Transporter Inhibition. NCI Thesaurus. Code C45555.

ABC Transporter Inhibition involves interference with, or restraint of, the activities of cell membrane glycoproteins selectively permeable to P-glycoprotein substrates. 